\title{
Profile of Snake Bite Deaths in South India: An Autopsy based Stud
}

\author{
Shanmugam $\mathbf{K}^{\mathbf{1}}$, Gerard Pradeep Devnath $\mathbf{S}^{\mathbf{2}}$ \\ ${ }^{1}$ Assistant Professor, Department of Forensic Medicine, Government Villupuram Medical College and Hospital, \\ Tamil Nadu, ${ }^{2}$ Assistant Professor, Department of Forensic Medicine, Sri Venkateshwaraa Medical College Hospital \\ and Research Center, Pondicherry
}

\begin{abstract}
Background: The burden due to the morbidity and mortality of snake bite in India is significantly higher. It is estimated around 1.2 million snakebite deaths (average 58,000/year) has occurred in India from the year 2000 to 2019. However the real burden of snake bite is unknown due to under reporting. This study aims to bring out region specific data on fatal snake bites

Results: The study was conducted at the dep of forensic medicine from 2016 to 2020 . A total of 75 cases of fatal snake bite cases were autopsied. The number of female cases 39 (52.3) and males were 36 (48.0). The maximum no 52 (69.4\%) cases were reported between the months of April to September. The common time for snake bite was in the night $40(53.3 \%)$ followed by the daytime $33(44.0 \%)$. The place of incidence where most of the bites happened was in and around the homes of the victims 46 (61.3) followed by the workplaces $29(38.7 \%)$. The commonest site were the bite mark was noted in the lower limbs 33 (44\%) cases. Around 22 $(23.9 \%)$ cases were seen in age groups of 45 to 59 years and $19(25.3 \%)$ cases in 35 to 44 years. The species of snake in majority of the cases i.e., $65(86.7 \%)$ was unknown. Around $40(53.3 \%)$ cases of kidney samples showed acute tubular followed by congestion.

Conclusion: The number of fatal bites were comparatively higher than that of the statistics available. Most of the findings of our study was consistent with the similar studies. The species of snake was largely unknown in this study because new snake species like hump nose pit viper can inflict fatal bites and are difficult to identify. Region specific data on snake bite will reflect the exact volume of snake bites in the country and would largely help in drafting policies to reduce mortality.
\end{abstract}

Keywords: Snake bite, gender, species of snake, acute tubular necrosis, autopsy

\section{Introduction}

Around 4.5-5.4 million people are bitten by snakes every year. Of which 81,000 to $1,38,000$ people died due to the complications of snake bite. ${ }^{(1)}$ In 2017, WHO

\section{Corresponding Author:}

\section{Gerard Pradeep Devnath S}

Assistant Professor, Department of Forensic Medicine

Sri Venkateshwaraa Medical College Hospital and Research Center, Pondicherry

Mail: drgerardfm@gmail.com

Cell: 9442934927 recognized snakebite envenoming as neglected tropical disease in 2017 and acknowledged that the mortality and morbidity due to snake bite is high in tropical and subtropical regions. WHO also highlighted that snake bites are being underestimated and called for ancoordinated international response was the need of the hour. ${ }^{(2)}$ Snake bites are common in Africa, Asia and Latin America. Around 2 million people are envenomed by snakes every year in Asia. ${ }^{(3)}$ It is estimated that around 1.2 million snakebite deaths (average 58,000/year) has occurred in India from the year 2000 to 2019 . Half of which occurred at ages 30-69 years and over a quarter in children $<15$ 
Medico-legal Update, October-December 2021, Vol.21, No. $4 \mathbf{3 4 3}$

years. ${ }^{(4)}$ As per the national health profile 2019 , issue by the central bureau of health intelligencearound 16,4031 cases of snakebites and 885 deaths were reported in India in the year 2018. ${ }^{(5)}$ Among the Indian states, Tamil Nadu is the most seriously affectedby snake bite and dataof it in various districts of Tamil Nadu is very sparse. (4)(6) This study will bring about the data regarding the age, sex, occupation, pace of incidence, site of bite, species of snake, time of bite and cause of death details in snake envenomation. This study conducted at the tertiary medical care center will highlight the snake bite profile at the Villupuram district.

\section{Materials and Methods}

This is an autopsy based study conducted at the department of Forensic Medicine, Villupuram government medical college, Mundiyampakkam, Tamilnadu from January 2016 to December 2020. Around 75 cases of fatal snake envenomation were analyzed during the study period. Institute ethical clearance was obtained for the study. The data on the variables such as age, sex, occupation, place of bite, site of bite, species of snake, time of bite, were collected from the hospital case sheets, police inquest copy and with history from the patient relatives at the time of autopsy.

\section{Results}

The study was conducted at the dep of forensic medicine from 2016 to 2020. A total of 75 cases of fatal snake bite cases were autopsied. A maximum of 19(25.33) cases were reported in the year 2017 and 16 cases 16 (21.3) in 2020. The minimum number of cases were reported in 2018 i.e., 14(18.7\%) cases. The total number of female were 39 (52.3) and males were 36 (48.0).Themaximum no 52 (69.4\%) cases were reported between the months of April to September.The least number of cases were reported in the month of January i.e., $2(2.7 \%)$. The common time for snake bite was in the night $40(53.3 \%)$ followed by the cases daytime 33 (44.0). The place of incidence, where most of the bites happened, was in and around the homes of the victims 46 (61.3) followed by the workplaces 29 (38.7\%). Workplaces included field, farms and brick kiln. Co relating with the time and place of incidence during night time $31(77.5 \%)$ of cases was reported in and around the house and 20(61.6\%) cases which occurred in day time was in workplaces. (Table 1)

The commonest site were the bite mark was noted in the lower limbs 33 (44\%) cases. The right lower limb was the site where most of the bite marks was located $(57 \%)$ and the zones include sole, dorsum, lateral, inner aspects of foot, ankle and below the knee joint. However in $24(32 \%)$ of cases the bite site was not detectable. In $15(20 \%)$ cases the bite site was in upper limbs of which $10(66 \%)$ were in right upper limb.

Around 22 (23.9\%) cases were seen in age groups of 45 to 59 years and 19 (25.3\%) cases in 35 to 44 years. Around 6 cases were noted in children age groups less than 15 years. (Table 2) Co relating the age group with place of incidence around 14 (63.6) cases occurred in workplaces in age group 45 to 69 years and $13(81.2 \%)$ cases occurred around the house or living area in age group 60 years and above.(Table 3) The species of snake in majority of the cases i.e., $65(86.7 \%)$ was not knows. However viper and cobra bites accounted for 6 and 4 cases respectively. (Table 4 )

Since it's anautopsy based study samples like bite site skin bit, kidneys and heart were sent for histopathology examination.Around 40 (53.3\%)cases of kidney samples showed acute tubular followed by congestion. (Table 5) The cause of death was opined as acute tubular due to snake bite in $40(53.3 \%) \%$ of the cases followed by effects of snake bite in 35(56.7\% ) of cases. (Table 6). 
Table 1: Co-relation between time of incidence and Place of incidence

\begin{tabular}{|c|c|c|}
\hline \multirow{2}{*}{ Time of incidence } & \multicolumn{2}{|c|}{ Place of Incidence } \\
\cline { 2 - 3 } & In and around house & $20(60.6 \%)$ \\
\hline Day time & $13(39.4 \%)$ & $9(22.5 \%)$ \\
\hline Night time & $31(77.5 \%)$ & 0 \\
\hline Not known & $2(100)$ & $29(38.7 \%)$ \\
\hline
\end{tabular}

Table 2: Age distribution of case

\begin{tabular}{|c|c|c|}
\hline Age & Frequency & Percentage \\
\hline$<15$ & 6 & 6 \\
\hline $15-29$ & 12 & 25.3 \\
\hline $30-44$ & 19 & 29.3 \\
\hline $45-59$ & 22 & 21.3 \\
\hline$>60$ & 16 & 100 \\
\hline
\end{tabular}

Table 3: co-relation between Age distribution and place of incidence

\begin{tabular}{|c|c|c|}
\hline \multirow{2}{*}{ Age } & \multicolumn{2}{|c|}{ Place of Incidence } \\
\cline { 2 - 3 } & In and around house & $3(25 \%)$ \\
\hline $15-29$ & $9(75 \%)$ & $9(47.4 \%)$ \\
\hline $30-44$ & $10(52.6 \%)$ & $14(63.6 \%)$ \\
\hline $45-59$ & $8(36.3 \%)$ & $3(18.8 \%)$ \\
\hline$>60$ & $13(81.2 \%)$ & $29(13.7 \%)$ \\
\hline
\end{tabular}

Table 4: Species of snake

\begin{tabular}{|c|c|c|}
\hline Species of snake & Frequency & Percentage \\
\hline Cobra & 4 & 5.3 \\
\hline viper & 6 & 86.7 \\
\hline Not known & 65 & 100 \\
\hline Total & 75 & 8 \\
\hline
\end{tabular}


Table 5: Results of histopathology examination of Kidney

\begin{tabular}{|c|c|c|}
\hline Histopathology findings & Frequency & Percentage \\
\hline Acute tubular necrosis & 40 & 53.3 \\
\hline Congestion & 30 & 40 \\
\hline Autolytic changes & 5 & 6.7 \\
\hline Total & 75 & 100 \\
\hline
\end{tabular}

Table 6: Cause of death

\begin{tabular}{|c|c|c|}
\hline Cause of death & Frequency & Percentage \\
\hline Acute tubular necrosis due to snake bite & 40 & 53.3 \\
\hline Effects of snakebite & 35 & 56.7 \\
\hline Total & 75 & 100 \\
\hline
\end{tabular}

\section{Dicussion}

The burden of snake bite in India is largely unknown. The major reason for this is due to mostly under reporting and no proper documentation. As per the National Health Profile 2019 14th Issue by the Central Bureau Of Health Intelligence 164031 cases of snakebites and 885 of deaths were reported in India in the year 2018. Of which 14,027 cases with 50 deaths were from Tamil Nadu. ${ }^{(5)}$ However the data regarding the number of deaths is very low. The no of snake bite deaths in the Villupuram district alone in 2018 was fourteen and thus this shows how under reported I the national statistics. A study by Peranantham reported 113 of fatal snake bite in two years in Coimbatore district alone. ${ }^{(7)}$ P. MOHANKUMAR reported 164 cases of snake bites in 1 year while other study by logaraj reported 106 cases of snake bites between January 2007 and December 2009.(8)(9) Sathish et al A reported 38 cases of fatal snake bite in two year in the Pondicherry, of which most of the cases were referred from Tamil nadu districts for further management. ${ }^{(\mathbf{1 0})}$ Thus ours is a only study in Tamil nadu that focused on fatal snake bite cases over a period of five year. A total of 75 fatal snake bite cases were documented between the years 2016 to 2020. Males were predominant in our study accounting for 39 cases $(52 \%)$ and is consistent with the similar studies in Tamil nadu and south India. ${ }^{(7-9)}$. Co-relating the gender with place of incidence most of the bites in males were in the workplace and in females the bites were mostly in and around of the house. The period of the year were maximum bites have occurred was in April to September of which the months of June and July had the maximum. As per the national data the maximumsnake bite deaths were in summer i.e., march-May (103 cases) and Monsoon i.e., june-september (299 cases). ${ }^{(6)}$ A 10 year study done across India showed $48 \%$ of the snake bite deaths occurred between June to September. ${ }^{(4)}$ The study by RekhaThapar et al and Peranantham showed snake bites were common in September to December (47.9\%) and February to March (27\%) respectively in their study. ${ }^{(7)(11)}$ 
The common age groups affected were between 45 to 60 years followed by 30 to 45 years, thus a total of $54.9 \%$ of the cases were between the age groups of 30 to 60 years. Our finding is consistent with the national snake bite mortality study which states that $57 \%$ of the victims were between the age groups 30 to 60 years. ${ }^{(4)}$ In another national study the majority of the victims were between the age group 15 to 29 years followed by 30 to 44 years. However the age distribution is consistent with the most of the regional and state studies.

The Big Four snakes i.e., the Russell's viper, Indian cobra, saw-scaled viper, and the common krait accounts for the major fatal bites in Indian subcontinent, Around $20 \%$ of the total 2700 snake species are venomous and they primarily belong to the Viperidae (vipers), Elapidae, Atractaspidae, and Colubridae. TheColubridae family comprises of $60 \%$ of all venomous snakes. The snakes of the Atractaspidae family, is known for burrowing into the ground and possessing the ability to expose their fangs without opening their mouth. ${ }^{(12)}$ However the hump nosed pit viper (Hypnalehypnale)bites as fatal as the big four and their fatal bits are mostly under reported. It is very difficult to identify the hump nosed pit viper and that is the main reason for most under reporting or misinterpretation to other snakes. In our study the species of snake implicated was not known in themajority of the cases. This maybe because of the following reasons such as the time of incidence, place of incidence, failure to observe the snake in fear and anxiety. However in 14 case the species were identified and of them viper were most common. The Russell's viper and krait were the most common species to inflict fatal bites in most of the national and regional studies. $\mathbf{( 4 , 6 - 9 , 1 1 , 1 3 , 1 4 )}$. However most of these studies have not commented about the hump nose pit viper bites which deliver the fatal bites as equal to the big four snakes. The incidence of fatal bites were most common in the night time $40(53.3 \%)$ and the victims have sustained the majority of the bites in and around their houses. Around 46 cases were between $12.00 \mathrm{pm}$ to $11.59 \mathrm{pm}$. In $29(38.7 \%)$ of the cases the bites were sustained in the work places. Lower limbs were the common body site for snake bite in $33(44 \%)$ cases and it 24 (3250 the bite marks were not appreciable. This may be due to the faint bite or due to neurotoxic bites. In a national study around $77 \%$ of cases the bites were located in the lower extremities. Surprisingly most of the bites were noted in the right lower extremities in our study Upper extremity bites were noted next to the lower extremity bites in the majority of the cases. ${ }^{(4,6-9,11,13,14)}$ Co relating with the time and place of incidence during night time $31(77.5 \%)$ of cases was reported in and around the house and $20(61.6 \%)$ cases which occurred in day time was in workplaces. Thus most of the bites were in the night time in and around the house.

The socio-cultural reason for the above findings may be due to the fact that most of the victims do not use protective foot wear while working in the fields, sleeping on the floor or ground, presence of livestock and hay stacks near the house and open air defecating in fields often when its dark. (15)

The most histopathology finding in kidney were acute tubular necrosis, followed by congestion and autolytic features. Study by Naqvi et al. and Sathish et al showed acute tubular necrosis in $44 \%$ of cases and $21(55.3 \%)$ cases respectively. ${ }^{(10)(16)}$ Renal findings are due to the nephrotoxicity of venom, immune complex disease, hemolysis, myoglobinuria, and sepsis ${ }^{(\mathbf{1 7})}$ the cause of death in most of the cases were opined as acute tubular necrosis due to snake bite and effect of snake bites in most of the cases. The cause of death was opined based as history, clinical features, and autopsy fining and histopathology findings.

\section{Conclusion}

Snakebite deaths in India still remains a s neglected subject and a important health burden. The exact data on snake bite epidemiology in the regional and national level statistics are contradictory in nature. A unified study across India with areas specific data will highlight the actual burden of snake bite in India. The concept of Big four snakes is outdated as new species of snakes are causing fatal bites. Species specific anti snake sera has to be developed based the geographically dominant snake 
species thereby reducing the mortality. Thus a team work by herpetologists, clinicians, autopsy surgeons and government can bring about more specific data in snake bite management. By doing so we India will be able to achieve the WHO's goal of reducing snakebite death and morbidity rates by 2030 .

\section{Conflict of Interest: Nil}

\section{Source of Funding:Nil}

Ethical Clearance: Taken from Institute Ethical Committee,

\section{References}

1. World Health Organization. Snakebite. Accessed on 10/03/2021. Available from: https://www.who. int/health-topics/snakebite\#tab=tab_1.

2. World Health Organization. Snakebite Envenoming. A strategy for prevention and control. Accessed on 10/03/2021.Available from: https://apps.who.int/iris/bitstream/hand le/10665/324838/9789241515641-eng.pdf?ua=1

3. World Health Organization. Snakebite envenoming global strategy for prevention and control of snakebite envenoming. Accessed on 10/03/2021. Available from: https://www.who. int/news/item/23-05-2019-who-launches-globalstrategy-for-prevention-and-control-of-snanebiteenvenoming

4. Suraweera W, Warrell D, Whitaker R, Menon G, Rodrigues $\mathrm{R}, \mathrm{Fu} \mathrm{SH}$, et al. Trends in snakebite deaths in India from 2000 to 2019 in a nationally representative mortality study. Elife. 2020;9:1-37.

5. Central Bureau Of Health Intelligence. National Health Profile (NHP) of India- 2019. Ministry of Health and Family Welfare. Accessed on 10/03/2021.. Available from: https://www. cbhidghs.nic.in/showfile.php?lid=1147

6. Mohapatra B, Warrell DA, Suraweera W, Bhatia P, Dhingra N, Jotkar RM, et al. Snakebite mortality in India: A nationally representative mortality survey.
PLoS Negl Trop Dis. 2011 Apr;5(4). e1018

7. Peranantham S, Jeyasingh T. An AutopsyBased Analysis Of Deaths Due To Snakebite Envenomation. J-SIMLA. 2018; 10(2):70-74.

8. Mohankumar DP, Sivagurunathan DC, Umadevi DR. Study on the clinico-epidemiological profile and the outcome of snake bite victims in a rural health centre in kancheepuram district, tamilnadu. Int J Pharm Bio Sci. 2015; 6(2):544 - 550.

9. Logaraj M, Thirumavalavan R, Gopalakrishnan S. Epidemiology of snakebite reported in a Medical College Hospital in Tamil Nadu. Int J Heal Allied Sci. 2013;2(1):53.

10. Sathish K, Shaha KK, Patra AP, Rekha JS. Histopathological profile of fatal snake bite autopsy cases in a tertiary care center in South India. Egyptian Journal of Forensic Sciences. 2021;11(1):1-8.

11. Thapar R, Darshan BB, Unnikrishnan B, Mithra P, Kumar N, Kulkarni V, etal. Clinico-epidemiological profile of snakebite cases admitted in a tertiary care Centre in South India: A 5 years study. Toxicol Int. 2015;22(1):66-70.

12. Whittaker R. Common Indian Snakes: A Field Guide [Internet]. New Delhi: McMillan India; 2006. 1-138 p.

13. Kshirsagar VY, Ahmed M, Colaco SM. Clinical profile of snake bite in children in rural India. Iranian journal of pediatrics. 2013;23(6):632.

14. Kilaribhaskar, Venkateswarrao S. A Retrospective Study of Snake Bites in Tirupati Region. Indian J Forensic Med Toxicol. 2019;13(3):29-33.

15. Menon JC, Joseph JK, Whitaker RE. Venomous snake bite in India-Why do 50,000 Indians die every year. J Assoc Physicians India. 2017;65(8):78-81.

16. Naqvi R. Acute kidney injury from different poisonous substances. World J Nephrol. 2017;6(3):162.

17. Chugh KS. Snake-bite-induced acute renal failure in India. Kidney Int. 1989;35(3):891-907. 